https://helda.helsinki.fi

\title{
Human urogenital myiasis : A systematic review of reported cases from 1975 to 2017
}

\section{Faridnia, Roghiyeh}

2019-04

Faridnia , R , Soosaraei , M , Kalani , H , Fakhar , M , Jokelainen, P , Emameh , R Z, Banimostafavi , E S \& Hezarjaribi , H Z 2019, ' Human urogenital myiasis : A systematic review of reported cases from 1975 to $2017^{\prime}$, European Journal of Obstetrics, and Gynecology ,and Reproductive Biology , vol. 235 , pp. 57-61 . https://doi.org/10.1016/j.ejogrb.2019.02.008

http://hdl.handle.net/10138/315578

https://doi.org/10.1016/j.ejogrb.2019.02.008

publishedVersion

Downloaded from Helda, University of Helsinki institutional repository.

This is an electronic reprint of the original article.

This reprint may differ from the original in pagination and typographic detail.

Please cite the original version. 
Review article

\title{
Human urogenital myiasis: A systematic review of reported cases from 1975 to 2017
}

\author{
Roghiyeh Faridnia ${ }^{\mathrm{a}}$, Masoud Soosaraei ${ }^{\mathrm{a}}$, Hamed Kalani ${ }^{\mathrm{b}}$, Mahdi Fakhar ${ }^{\mathrm{c}, *}$, \\ Pikka Jokelainen ${ }^{\mathrm{d}, \mathrm{e}, \mathrm{f}}$, Reza Zolfaghari Emameh ${ }^{\mathrm{g}}$, Elham Sadat Banimostafavi ${ }^{\mathrm{h}}$, \\ Hajar Ziaei Hezarjaribic \\ a Student Research Committee, Mazandaran University of Medical Sciences, Sari, Iran \\ b Infectious Diseases Research Centre, Golestan University of Medical Sciences, Gorgan, Iran \\ ${ }^{\mathrm{c}}$ Toxoplasmosis Research Center, Department of Parasitology, School of Medicine, Mazandaran University of Medical Sciences, Sari, Iran \\ d Laboratory of Parasitology, Department of Bacteria, Parasites and Fungi, Infectious Disease Preparedness, Statens Serum Institute, Copenhagen, Denmark \\ e University of Helsinki, Helsinki, Finland \\ ${ }^{\mathrm{f}}$ Estonian University of Life Sciences, Tartu, Estonia \\ ${ }^{\mathrm{g}}$ Department of Energy and Environmental Biotechnology, Division of Industrial and Environmental Biotechnology, National Institute of Genetic Engineering \\ and Biotechnology, Tehran, Iran \\ ${ }^{\mathrm{h}}$ Department of Radiology, Imam Khomeini Hospital, School of Medicine, Mazandaran University of Medical Sciences, Sari, Iran
}

\section{A R T I C L E I N F O}

\section{Article history:}

Received 29 June 2018

Received in revised form 3 December 2018

Accepted 4 February 2019

\section{Keywords:}

Human

Myiasis

Systematic review

Urogenital

\begin{abstract}
A B S T R A C T
The public health importance of myiasis [infestation with dipterous (fly) larvae] remains unknown. This disease is spread worldwide in animals and humans, but baseline data on its prevalence are limited. In particular, knowledge on human urogenital myiasis (UGM) is scattered. As such, a systematic search was undertaken of five English and five Persian databases for publications describing UGM cases in English or Persian published between 1975 and 2017. In total, 45 papers reporting 59 UGM cases from various regions of the world are included in this review. All included papers were from the English databases. The age of patients ranged from 5 to 89 years, and the mean age was 40.6 years. Thirty-six of the patients were female and 19 were male. The highest number of cases $(n=12)$ was reported from Brazil. The most common genera causing UGM were Psychoda spp. (23.7\%) and Cochliomyia spp. (11.8\%). The vagina was the most commonly reported anatomical location of UGM for women, and the urogenital tract was the most commonly reported location for men. Thirteen cases were reported from rural areas and eight cases from urban areas; the location of other cases was not specified. The incidence of UGM is likely to be substantially underestimated when evaluated based on published case reports. Epidemiological studies, such as questionnaires to medical doctors, could help to gather the necessary baseline data on the occurrence of UGM.
\end{abstract}

(C) 2019 Elsevier B.V. All rights reserved.

\section{Contents}

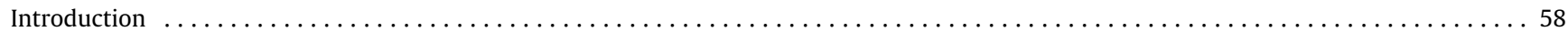

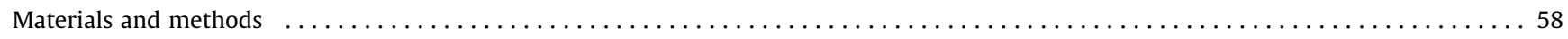

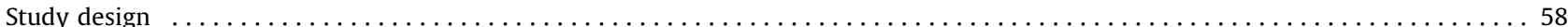

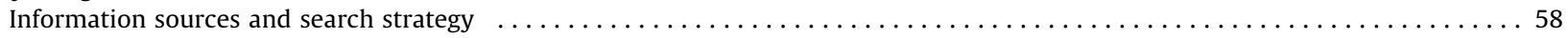

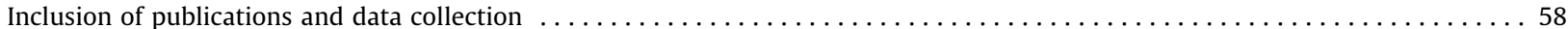

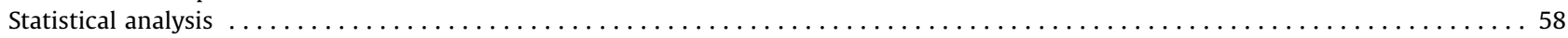

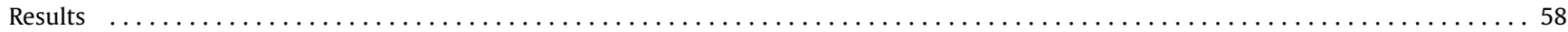

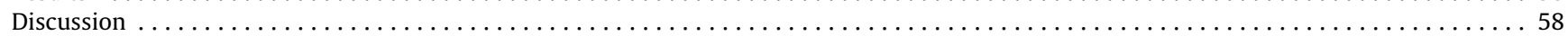

\footnotetext{
* Corresponding author at: Toxoplasmosis Research Center, School of Medicine, Department of Parasitology, Mazandaran University of Medical Sciences, FarahAbad Road, P.O. Box 48471-91971, Sari, Iran.

E-mail address: mahdif53@yahoo.com (M. Fakhar).
} 


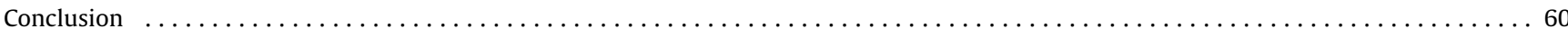

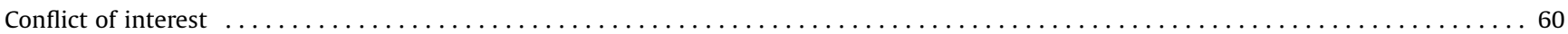

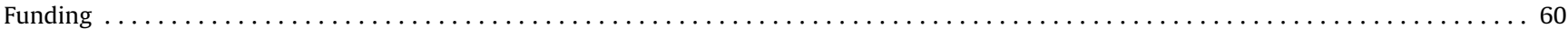

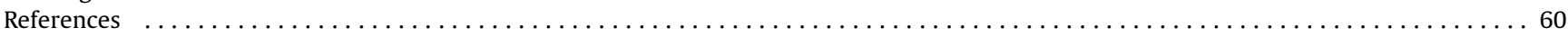

\section{Introduction}

Myiasis is a parasitic disease caused by the presence of dipterous (fly) larvae in living or dead tissues of live vertebrates (i.e. animals and humans). Entry of the larvae occurs through skin wounds or body cavities, such as the mouth, ears, eyes and urogenital tract. The larvae are able to pierce and penetrate both healthy and necrotic tissues; therefore, tetanus and secondary infection may occur as complications of myiasis [1,2]. In humans, the infestation is endemic in some areas and travel-related in other areas [2]. The disease is associated with socio-economically poor regions, certain cultural habits, and favourable weather conditions for flies [2]. The reported predisposing risk factors for human myiasis include poor hygiene, advanced age, diabetes, psychiatric illness, rural background, low socio-economic status and homelessness [2,3].

Based on the parts of the body involved, myiasis is classified into different types, including cutaneous, subcutaneous, nasopharyngeal, intestinal and urogenital (UGM) $[2,3]$. Based on the relationship between the host and the larvae, myiasis can also be classified into obligatory, facultative and accidental myiasis. Several fly families, genera and species can cause myiasis $[2,4]$.

Symptoms of UGM vary according to the organ involved and the severity of infection $[5,6]$. The only definitive treatment of UGM is to remove the larvae, and in such cases, the symptoms will disappear thereafter [7]. Consequently, correct diagnosis is necessary in order to avoid unnecessary treatment [8].

Currently, the real burden of myiasis is unknown, and baseline data on its prevalence are limited and scattered. For this reason, UGM can be considered as a neglected disease. Moreover, UGM diagnosis may be confused because no specific symptoms associated with this infestation are known, so awareness of this infestation is of major importance in order to be reported correctly by physicians. As such, a systematic review of publications reporting cases of UGM was undertaken to clarify the latest status of this disease in the literature.

\section{Materials and methods}

\section{Study design}

This systematic review was not preregistered. The search process, screening and selection was systematically designed and performed as follows.

\section{Information sources and search strategy}

Ten databases were included as information sources in the search for reports on UGM. Five were English databases (PubMed, Google Scholar, ScienceDirect, Scopus and Web of Science) and five were Persian databases [Magiran, Irandoc, ELM net, Barakat Knowledge Network System (formerly Iran medex) and Scientific Information Database]. No further searches (e.g. from reference lists of the papers) were performed.

The search was performed using the following terms: myiasis, screwworm, maggot, human, urogenital, genitalia, vulva, vagina, vulvovaginal, penis, penile, urethra and urinary tract, in combination with each other. Any written papers in English or Persian, published between 1975 and 2017 (42 years), reporting case(s) of UGM were considered for screening, regardless of study design.
Inclusion of publications and data collection

In total, 361 records were identified, 96 of which were duplicates (Fig. 1). Papers reporting the same findings and papers that were not about humans were also excluded. Four reviewers (RF, MS, HK and HZH) screened the remaining papers independently for inclusion in the review. Disagreements were resolved by MF.

The following data were extracted from the papers included in the review: year of publication, first author, age and sex of patient (s), country, rural or urban place of residence, organ involved, and species of fly. There was no contact with the authors of the papers. Risk of bias of individual studies was not formally assessed; publication bias was expected.

\section{Statistical analysis}

Data were analysed using SPSS v16 (IBM Corp., Armonk, NY, USA) and presented as proportions (\%). Moreover, Chi-squared test and two-tailed $t$-test were utilized to compare proportions in each group, and $p<0.05$ was considered to indicate significance.

\section{Results}

Overall, from the 10 databases searched, 45 papers were included in the review (Fig. 1) [5-49]. All 45 papers were from the English databases. All the papers were UGM case reports or UGM case series, and reported a total of 59 cases of UGM from various regions of the world (Appendix 1 in supplementary material).

Analysis of the cases based on the extracted data is shown in Table 1 . The age range of patients was 5-89 years old, and the mean age was 40.6 years. Nine patients were under 18 years of age. Thirtysix females and 19 males were included, and the patient's sex was not reported in four studies. Of the 59 cases, most were from Asian countries ( $n=19,10$ of which were from India), followed by American countries ( $n=16,12$ of which were from Brazil), European countries ( $n=13$ cases) and African countries $(n=8)$. The place of residence was reported for 21 patients: 13 patients lived in rural areas and eight patients lived in urban areas. The most frequently reported common fly species causing UGM were Psychoda spp. (23.7\%) and Cochliomyia spp. (11.8\%) (Appendix 2 in supplementary material). The vagina was the most commonly reported anatomical location of UGM for women, and the urogenital tract was the most commonly reported location for men. The infestation rate was higher in women (61\%) than men (32.2\%).

\section{Discussion}

Publications reporting UGM are few in number and unevenly distributed geographically. Between 1975 and 2017, cases of UGM were mainly reported from Asia and South America, particularly from India and Brazil. These and other tropical and subtropical regions are considered typical for myiasis, whereas the disease is rare and considered as travel-related in developed countries with good healthcare systems, especially in Central Europe [2]. However, the Brazilian and Indian healthcare systems are more active to report interesting clinical findings [50]. Considering the reviewed studies, physicians are not usually expert to identify myiasis because cases of this disease are rare and the symptoms are not specific. Infestations are reported from both developed and 


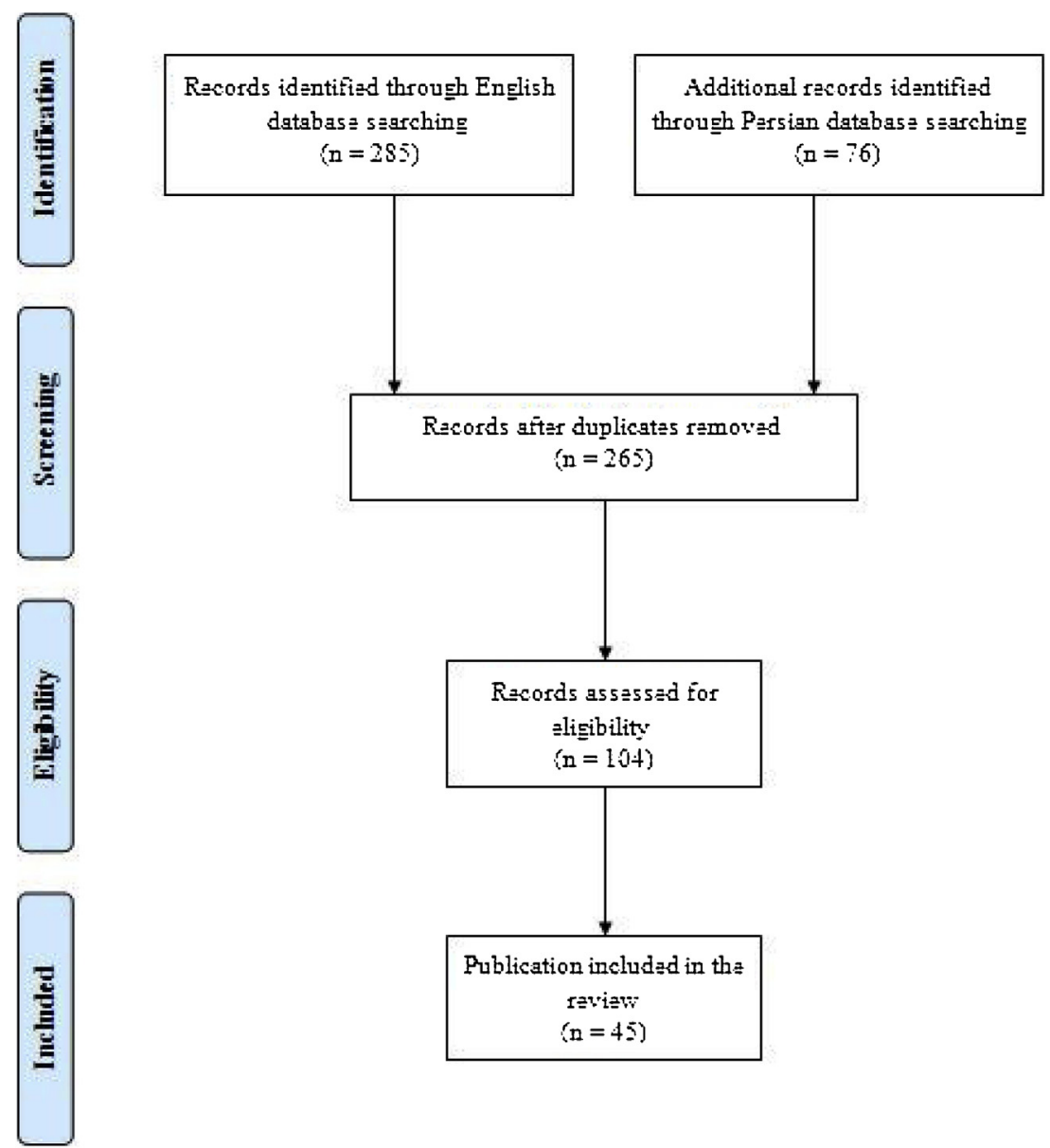

Fig. 1. PRISMA flow diagram showing the selected articles.

Table 1

Analysis of human urogenital myiasis according to the extracted variables.

\begin{tabular}{|c|c|c|c|}
\hline$p$-value & $n(\%)$ & Category & Variable \\
\hline \multirow[t]{2}{*}{$<0.05$} & $6(10.1)$ & 1975-1995 & Year \\
\hline & $53(89.8)$ & 1996-2017 & \\
\hline \multirow[t]{6}{*}{$>0.05$} & $15(25.4)$ & $\leq 20$ & Age (years) \\
\hline & $16(27.1)$ & $>20 \leq 40$ & \\
\hline & $8(13.5)$ & $>40 \leq 60$ & \\
\hline & $12(20.3)$ & $>60 \leq 80$ & \\
\hline & $4(6.7)$ & $>80$ & \\
\hline & $4(6.7)$ & NR & \\
\hline \multirow[t]{3}{*}{$<0.05$} & $36(61)$ & Female & Gender \\
\hline & $19(32.2)$ & Male & \\
\hline & $4(6.7)$ & NR & \\
\hline \multirow[t]{7}{*}{$>0.05$} & $12(20.3)$ & Brazil & Country \\
\hline & $10(16.9)$ & India & \\
\hline & $7(11.8)$ & Turkey & \\
\hline & $7(11.8)$ & Egypt & \\
\hline & $5(8.4)$ & Iran & \\
\hline & $15(25.4)$ & Other & \\
\hline & $3(5)$ & NR & \\
\hline \multirow[t]{3}{*}{$>0.05$} & $8(13.5)$ & Urban & Living area (urban/rural) \\
\hline & $13(22)$ & Rural & \\
\hline & $38(64.4)$ & NR & \\
\hline \multirow[t]{7}{*}{$>0.05$} & $20(33.8)$ & Urogenital & Organ involved \\
\hline & $11(18.6)$ & Vagina & \\
\hline & $5(8.4)$ & Labia & \\
\hline & $8(13.5)$ & Urethra & \\
\hline & $6(10.1)$ & Vulva & \\
\hline & $4(6.7)$ & Vulvovagina & \\
\hline & $7(11.8)$ & Other & \\
\hline
\end{tabular}

NR, not reported. developing countries, as low-income individuals are also susceptible to infestation in developed countries [49].

The clinical symptoms of UGM are variable; some patients remain asymptomatic and others display severe symptoms. General symptoms include abdominal pain, nausea, itching, rectal bleeding, vomiting and side pain [5]; and specific symptoms include dysuria, pollakiuria, haematuria, and larvae in urine [51]. Urethral involvement as an obstacle to urine flow has been reported in both women and men [10,12]. Involvement of the external parts of the female genitalia, especially the lamina minora and lamina majora, is often accompanied by symptoms such as tenderness, erythema and inflammation $[17,19,33]$. The symptoms of UGM are very variable when the vagina is involved, leading to misdiagnosis, and often include the aforementioned general symptoms [6]. Such symptoms may also be observed when the internal parts of the penis are involved [18]. When the glans penis is involved, lesions may be observed as ulcers [24].

Myiasis is often mistakenly diagnosed because the disease is very rare and its symptoms are not specific [7], and incorrect diagnosis can lead to unnecessary treatment [8]. UGM can be misdiagnosed as an obstructing ureteral stone [44]. Endoscopy can be used to diagnose and treat internal UGM [2]. Although biochemical examination is not beneficial for diagnosis, microhaematuria, albuminuria and leukocyturia may be observed in patients with myiasis [6,39]. According to the reviewed articles, the best way to diagnose cases where the larvae are not visible is to take a history from the patient [2].

Treatment of UGM varies according to the localization of larvae and the severity of the symptoms. There is no specific treatment as 
larvae are insensitive to drugs. Often, initial treatment with antibiotics is useless due to misdiagnosis [24]. Mechanical removal of larvae, if they can be reached, is the best and only definitive treatment of UGM, and the use of antibiotics with antiinflammatory drugs, if the symptoms are severe, is a therapeutic option $[2,3,15,52]$. In some patients, additional treatment may also be needed [53].

This review found no significant difference between rural and urban areas $(p>0.05)$; however, myiasis occurs mainly in rural areas, and there is an indirect relationship between self-perceived poor health, education level and myiasis [37]. Myiasis is more common in individuals with mental health problems, diabetes, immunodeficiency and low socio-economic status [24]. When parts of the urogenital system are exposed to flies, they are attracted to lay eggs or larvae in the genital cavities due to the unpleasant odour. Furthermore, individual habits, such as lying on the ground naked and poor hygiene, increase the risk of myiasis [54].

This review also found that infestation rates in women were higher than in men, and the most common organ involved in women was the vagina. Genital myiasis may occur through fly eggs transferring through dusty clothes to the vulva or glans penis [24]. It has been shown previously that some villagers dry washed their clothes on the ground, and flies lay eggs in the material leading to larvae attacking the host [33]. In addition, flies that lay eggs in genital cavities may have been attracted by the scent brought about by poor cleanliness and genital co-infections, and individuals that do not wear underwear outside or after or during intercourse may also have more infections [36].

Symptoms will be relieved after removing the maggots. In some cases, there are secondary bacterial and or Trichomonas vaginalis infections that should be treated with broad-spectrum antimicrobial agents [55].

This systematic review indicates that UGM is common in several tropical countries, mainly in Asia and South America. The authors believe that UGM cases worldwide are more common than the literature suggests, as there are likely to have been cases that have not been reported by physicians. In addition, in some of the articles reviewed in the current study, the genera of the larvae were not identified, and this important issue should be considered by researchers and physicians. As a whole, regular monitoring of individuals is required to improve public health education, particularly personal health care and environmental sanitation in regions with a high incidence of infestations, which can reduce sociopsychiatric obstacles caused by UGM in the community.

\section{Conclusion}

This systematic review found that UGM has been observed in several countries, mainly from Asia and South America. The incidence of UGM is likely to be substantially underestimated when evaluated based on published case reports.

\section{Conflict of interest}

None declared.

\section{Funding}

This study was financially supported by Mazandaran University of Medical Sciences, Sari, Iran (Grant No: 2795).

\section{Appendix A. Supplementary data}

Supplementary material related to this article can be found, in the online version, at doi:https://doi.org/10.1016/j.ejogrb.2019.02.008.

\section{References}

[1] Diaz JH. The epidemiology, diagnosis, management, and prevention of ectoparasitic diseases in travelers. J Travel Med 2006;13:100-11.

[2] Francesconi F, Lupi O. Myiasis. Clin Microbiol Rev 2012;25:79-105.

[3] Ramana K. Human myiasis. J Med Microbiol Diagnos 2012;1:e105.

[4] John D, Petri Jr W. Markell and Voge's medical parasitology. Missouri: Saunders Elsevier; 2006. p. 22-45 2006.

[5] Demir AD, Iraz M, Ipek DN. Urogenital myiasis caused by Psychoda albipennis in a child. Turk Pediatri Ars 2015;50:65-8.

[6] Taylan-Ozkan A, Babur C, Kilic S, Nalbantoglu S, Dalkilic I, et al. Urogenital myiasis caused byPsychoda albipennis (Diptera: Nematocera) in Turkey. Int J Dermatol 2004;43:904-5.

[7] Predy G, Angus M, Honish L, E Burnett C, Stagg A. Myiasis in an urban setting: a case report. Can J Infect Dis 2004;15:51-2.

[8] Culha MG, Turker K, Ozsoy S, Serefoglu EC. Urogenital myiasis caused by Psychoda albipennis. Saudi Med J 2016;37:1401-3.

[9] Granz W, Schneider D, Schumann H. [Human myiasis in middle Europe]. Z Gesamte Inn Med 1975;30:293-301.

[10] Jdalayer T, Maleki M, Moghtaderi M. Human urogenital myiasis caused by Chrysomyia bezziana. Iran J Pub Health 1978;7:116-9.

[11] Biery TL, Clegern RW, Hart WW. Two cases of phorid (Diptera: Phoridae) myiasis in Texas. J Med Entomol 1979;15:122-3.

[12] Singh TS, Rana D. Urogenital myiasis caused byMegaselia scalaris (Diptera: Phoridae): a case report. J Med Entomol 1989;26:228-9.

[13] Cilla G, Pico F, Peris A, Idigoras P, Urbieta M, et al. [Human genital myiasis due to sarcophaga]. J Egypt Soc Parasitol 1992;190:189-90.

[14] Saleh MS, el Sibae MM. Urino-genital myiasis due to Piophila casei. J Egypt Soc Parasitol 1993;23:737-9.

[15] Passos MR, Varella RQ, Tavares RR, et al. Vulvar myiasis during pregnancy. Infect Dis Obstet Gynecol 2002;10:153-8.

[16] Dahiya K, Khosla AH. Vulvo-vaginal infestation with maggots. Int J Gynaecol Obstet 2002;79:55-6.

[17] Yazar S, Ozcan H, Dincer S, Sahin I. Vulvar myiasis. Yonsei Med J 2002;43:553-5.

[18] Hyun DY, Cain MP, Blue-Hnidy DE, Conway JH. Urinary myiasis associated with ureteral stent placements. Ped Infect Dis J 2004;23:179-81.

[19] Chan JC, Lee JS, Dai DL, Woo J. Unusual cases of human myiasis due to Old World screwworm fly acquired indoors in Hong Kong. Trans R Soc Trop Med Hyg 2005;99:914-8.

[20] da Silva BB, Borges US, Pimentel IC. Human vaginal myiasis caused by Cochliomyia hominivorax. Int J Gynaecol Obstet 2005;89:152-3.

[21] Chigusa Y, Shinonaga S, Honda M, et al. Vaginal myiasis due to Sarcophaga peregrina (Diptera: Sarcophagidae) on a patient with atrial fibrillation, cerebral infarction and leg amputation. Med Entomol Zool 2005;56:247-9.

[22] Wadhwa V, Kharbanda P, Rai S, Uppal B. Urogenital myiasis due to Chrysomyia bezziana. Indian J Med Microbiol 2006;24:70-1.

[23] Lopes-Costa PV, dos Santos AR, Pereira-Filho JD, da Silva BB. Myiasis in the uterine cavity of an elderly woman with a complete uterine prolapse. Trans R Soc Trop Med Hyg 2008;102:1058-60.

[24] Passos MR, Ferreira DC, Arze WN, Silva JC, Passos FD, Curvelo JA. Penile myiasis as a differential diagnosis for genital ulcer: a case report. Braz J Infect Dis 2008;12:155-7.

[25] Wakid MH. A laboratory-based study for first documented case of urinary myiasis caused by larvae of Megaselia scalaris (Diptera: Phoridae) in Saudi Arabia. Kor J Parasitol 2008;46:33-6.

[26] Abe DK, Rosa RT, Dall'Oglio MF, Froes MH, Almeida BC, Said LA. Urethral myiasis. Braz J Infect Dis 2009;13:248.

[27] Baidya J. A rare case of genital myiasis in a woman with genital prolapse and malignancy and review of the literature. Ann Trop Med Public Health 2009;2:29.

[28] Shakoor S, Beg MA. An unusual urinary tract infection! Myiasis. Neth J Med 2010;68:323-6.

[29] Salimi M, Goodarzi D, Karimfar M, Edalat H. Human urogenital myiasis caused byLucilia sericata (Diptera: Calliphoridae) and Wohlfahrtia magnifica (Diptera: Sarcophagidae) in Markazi Province of Iran. Iran J Arthropod Borne Dis 2010;4:72-6.

[30] Saldarriaga W, Herrera E, Castro D. Myasis in uterine prolapse, successful treatment. Am J Obstet Gynecol 2011;205:e5-6.

[31] Oğuz U, Reşorlu B, Çizmeci Z, Ünsal A. A rare urogenital myiasis caused by Psychoda albipennis: a case report. Turk J Urol 2012;38:168-9.

[32] Barabas-Hajdu E, Satan E, Mihaly A. Urogenital myiasis: a human case report. Acta Microbiol Immunol Hung 2012;59:469-73.

[33] Kataria U, Siwach S, Gupta S. Myiasis in female external genitalia. Indian J Sex Transm Dis AIDS 2013;34:129-31.

[34] Garbeloto E, de Souza-Trindade B, Alves-Canal F, Chambô-Filho A. Genital and breast myiasis: case series. J Trop Med Parasitol 2013;36:98-104.

[35] Kovaleva A, Climent PC, Becares CV, Martin Azana MJ, Irishina N, et al. Urogenital myiasis by Cordylobia anthropophaga. J Pediatr Adolesc Gynecol 2013;26:e123-5.

[36] Ziaei Hezarjaribi H, Taghavi M, Fakhar M, Seyrafi A, et al. Vaginal myiasis due to Fannia scalaris. Int J Gynaecol Obstet 2014;127:300.

[37] Yones DA, Bakir HY, Hameed DA. Human urogenital myiasis caused by Psychoda species larvae: report of five cases and morphological studies. History 2013. 
[38] El-Badry AA, Salem HK, El-Aziz Edmardash YA. Human urinary myiasis due to larvae ofClogmia (Telmatoscopus) albipunctata Williston (Diptera: Psychodidae) first report in Egypt. J Vector Borne Dis 2014;51:247-9.

[39] Ghavami MB, Djalilvand A. First record of urogenital myiasis induced byMegaselia scalaris (Diptera: Phoridae) from Iran. J Arthropod Borne Dis 2015;9:274-80.

[40] Mondal PC, Mahato S, Chakraborty B, Sinha SK. First report of Oriental latrine flies causing vaginal myiasis in human. J Parasit Dis 2016;40:1243-5.

[41] Pandey D, Divedi P, Mishra PK, Mishra P. Vulval myiasis: an unusual presentation of a rare entity in an adolescent female. Trop Parasitol 2015;5:58-60.

[42] Karagüzel E, Kutlu O, Buruk K, Okatan AE, Özgür GK. Urogenital myiasis caused by Psychoda albipennis: a case report. Afr J Urol 2015;4:195-6.

[43] Serefoglu EC. P-03-073 Urogenital myiasis caused by Psychoda albipennis: a case report. J Sex Med 2016;13:S209-10.

[44] Rasti S, Dehghani R, Khaledi HN, Takhtfiroozeh SM, Chimehi E. Uncommon human urinary tract myiasis due to Psychoda sp. larvae, Kashan, Iran: a case report. Iran J Parasitol 2016;11:417-21.

[45] Soulsby H, Jones BL, Coyne M, Alexander CL. An unusual case of vaginal myiasis. JMM Case Rep 2016;3:e005060.

[46] Saadawi WK, Shaibi T, Annajar BB. A human case of urogenital myiasis caused byPsychoda sp. larvae in Tripoli, Libya. Ann Parasitol 2017;63:69-71.
[47] Lwanga A, Anis M, Ayoubi M, Sharma J, Khosla P. Two cases of myiasis associated with malignancies in patients living in the continental United States. Cureus 2018;10:e2049.

[48] El-Dib NA, El Wahab WMA, Hamdy DA, Ali MI. Case report of human urinary myiasis caused byClogmia albipunctata (Diptera: Psychodidae) with morphological description of larva and pupa. J Arthropod Borne Dis 2017;11:533-8.

[49] Nagy V. Unusual presentation of the urogenital myiasis caused byLuciliasericata (Diptera: Calliphoridae). Ann Agric Environ Med 2012;19:802-4.

[50] Gopalakrishnan S, Srinivasan R, Saxena SK, Shanmugapriya J. Myiasis in different types of carcinoma cases in southern India. Indian J Med Microbiol 2008;26:189.

[51] Sahin AR, Olker U, Nazik S, Guler S, Kirecci E. Urogenital myiasis caused by Psychoda albipennis. Turk Parazitol Derg 2018;42:93-5.

[52] Kaya S, Arslan M, Karaer Z, Köksal İ. Psychoda albipennisin neden olduğu ürogenital myiasis. Türk Parazitol Derg 2011;35:172-4.

[53] Passos MR, Barreto NA, Varella RQ Rodrigues GH, Lewis DA. Penile myiasis: a case report. Sex Transm Infect 2004;80:183-4.

[54] Ergün S, Akıncı O, Sirekbasan S, Kocael A. Postoperative wound myiasis caused by Sarcophaga carnaria. Turkiye Parazitol Derg 2016;40:172-5.

[55] Sapre AS, Natu VN, Patel MV, Chandwaskar N. Rare case of urogenital myiasis. J Obstet Gynecol India 2013;63:145-6. 